Synthesis

\title{
How Useful Are Species Distribution Models for Managing Biodiversity under Future Climates?
}

\author{
$\underline{\text { Steve J. Sinclair }}^{1}, \underline{\text { Matthew D. White }}^{1}$, and Graeme R. Newell ${ }^{1}$
}

\begin{abstract}
Climate change presents unprecedented challenges for biological conservation. Agencies are increasingly looking to modeled projections of species' distributions under future climates to inform management strategies. As government scientists with a responsibility to communicate the best available science to our policy colleagues, we question whether current modeling approaches and outputs are practically useful. Here, we synthesize conceptual problems with species distribution models (SDMs) associated with interspecific interactions, dispersal, ecological equilibria and time lags, evolution, and the sampling of niche space. Although projected SDMs have undoubtedly been critical in alerting us to the magnitude of climate change impacts, we conclude that until they offer insights that are more precise than what we can derive from basic ecological theory, we question their utility in deciding how to allocate scarce funds to large-scale conservation projects.
\end{abstract}

Key Words: climate policy; climatic envelope; decision support; distribution modeling; niche; spatial modeling; species interaction.

\section{INTRODUCTION}

Ecological systems face significant threats from climate change, and the need for effective responses is becoming a public policy imperative in many jurisdictions (Hannah et al. 2002, Stern 2006). There has long been agreement that climate change will force some species to shift their geographic ranges, or face extinction (Parmesan 1996, 2006, Massot et al. 2008, Vos et al. 2008). Proactive responses to ameliorate such impacts have been proposed. These include species translocation (Hoegh-Gulberg et al. 2008) and construction of dispersal routes to assist species to track shifting climates (Phillips et al. 2008). Such bold thinking is welcome, but how do we decide when and where to best implement these strategies? Which species will be under most threat, and where must they move in order to avoid extinction?

Species distribution models (SDMs) that incorporate future climate predictions are one popular way to address these questions (and a range of other questions discussed below). These models are a prominent fixture in the scientific, policy, and public literature around the potential impacts of climate change. Particularly wide attention was given to the work of Thomas et al. (2004; see Ladle et al. 2004, Hannah and Phillips 2004, Lewis 2006).

Given the potential of SDMs to influence policy and management, we believe it is timely to critically appraise how they are interpreted and used in this context. As government scientists, we endeavor to develop and communicate the best available science to colleagues charged with management and policy decisions. From this viewpoint, we question how helpful SDMs are for critical decisions when formulating policies or guiding governmental investments. We review the pitfalls and hidden assumptions in the most common modeling techniques from an ecological science perspective. Our discussion differs from other review articles on this topic (e.g., Davis et al. 1998a, b, Pearson and Dawson 2003, Hampe 2004, Guisan and Tuiller 2005, Hulme 2005, Hijmans and Graham 2006, Dormann, 2007) in its broad ecological scope, its attempt to distinguish systematic tendencies to overor under-predict caused by inherent aspects of the models, and in its perspective from the sciencepolicy interface. 


\section{SDMs: DEFINITION AND SCOPE OF OUR DISCUSSION}

Species distribution models may be constructed in a variety of ways and result in a range of outputs. Most attempt to predict species' geographic ranges from occurrence (presence; or presence/absence) records (dependent variable) and environmental data from the same sites (independent variables). Two types of output are common: binary classifications of sites as being within or outside the distribution, and continuous or probabilistic results. The parameters may be projected using future climate scenarios to develop maps of predicted future distributions. Our discussion of SDMs is focused on this use as predictive tools under climate change, and most references to SDMs should be considered in the context of this "special case."

Species distribution models of different levels of complexity fit within this basic framework (e.g., those that use only climate as independent variables vs. those that also use biophysical variables). Less common are species-climate models not driven by distributional data at all (not considered here), such as those constructed from physiological measurements of organisms (e.g., Kearney et al. 2008). Species distribution models can be developed using a variety of algorithms, including heuristic models (e.g., BIOCLIM-Beaumont and Hughes 2002), statistical models (e.g., GAMs-Jensen et al. 2008), combinatorial optimization (e.g., GARP-Fitzpatrick et al. 2007) and machine learning (e.g., ANNOstendorf et al. 2001, Berry et al. 2002, Harrison et al. 2006; MAXENT_Phillips et al. 2006). Some studies have pooled multiple models or applied other principles (notably species-area relationships) to extrapolate global extinction rates from climate change (Thomas et al. 2004). Each modeling approach has important strengths and weaknesses. Performance is generally assessed using a test or validation data set (Elith et al. 2006, Hijmans and Graham 2006).

Fielding and Bell (1997) distinguish between errors resulting from the statistical limitations of models ("algorithmic") and errors resulting from (mis-) understandings of the biological system ("biotic"). Our focus here is on the biotic errors. We do not consider algorithmic errors, given the numerous modeling approaches available, and the positive progress being made in this area (Elith et al. 2006). We also ignore several biological issues conceptually trivial in our context (e.g., taxonomic problems), but nonetheless influential. Some of the principles we discuss in relation to future climate models are applicable elsewhere, for example in predicting the ranges of introduced species (Fitzpatrick et al. 2007). Here, we use "biodiversity" in a narrow sense to mean "species diversity" while acknowledging that in the wider public debate, the term may refer to diversity at other levels (genetic, ecosystem, etc.). Although we acknowledge the central importance of atmospheric or climate change models for projected SDMs, their substance is beyond our scope.

\section{FACTORS IMPACTING THE DESIGN AND UTILITY OF SPECIES-CLIMATE MODELS}

Basic ecological assumptions-both reasonable and problematic-underpin most SDMs. Some relate to inherent ecological processes that determine species' distributions and abundances, whereas others are methodological and concern the way data are used in SDMs. Although we have attempted to disaggregate these for the sake of clarity, we recognize that many of these factors are deeply interrelated.

\section{Biological Factors}

\section{Interspecific interactions}

Virtually all SDMs implicitly accept the classical niche concept: that the distributions of species are constrained by interactions with other organisms such as competition and predation (i.e., realized vs. fundamental niche; Hutchinson 1957). This idea has a long history and has been experimentally demonstrated in numerous systems (Connell 1961, Crain et al. 2004). We accept this useful view of niche as it relates to species' distributions, but it presents a constraint on the interpretation of SDMs.

Despite the recognition of interspecific interactions, and their likelihood of changing with an altering climate, SDMs almost never account for this. Most authors ignore interspecific interactions, whereas some assume they are of some importance (Erasmus et al. 2002, Midgeley et al. 2002). Others acknowledge the limitations these interactions place on their models and assume that these effects will be unpredictable under climate change and "idiosyncratic" (Lewis 2006). We suggest that there are logical reasons why the effects of these 
interactions will regularly lead to underestimates of future species' ranges (Table 1).

Observations of organisms in nature will be by definition within the realized niche. When a model is developed using these records, all interspecific interactions are implicit within the model (Davis et al. 1998b). When the SDM is projected from the current to a future climate scenario, these effects and constraints are ignored. It is wrongly assumed that all other species interacting with the target species do so with unmodified amplitude within future climate scenarios. Provided negative interactions (competition, predation, etc.) outweigh positive interactions (mutualism, synergism, etc.) almost all target species are at an inherent (and illusory) disadvantage caused by the modeling approach. One of many practical examples that illustrate this is reported by Fitzpatrick et al. (2007), who show that when distributional data from the native range of a fire ant (South America) were used to predict the species' range in a new habitat (North America), the model dramatically under-predicted the actual introduced range of the species. They concluded that this was due, at least in part, to altered interspecific interactions. This concurs with the niche shift observed during a biological invasion of spotted knapweed (Centaurea maculosa; Broennimann et al. 2007). Other studies have used "theoretical species" to show that interspecific interactions impact on the ability of a species to survive simulated climate change (Brooker et al. 2007, Best et al. 2007). An elegant experimental study also addressed similar concerns. Davis et al. (1998b) used captive fruit-flies (Drosophila melanogaster) to show that temperature changes strongly interacted with competition, leading these authors to conclude that "predicting changes in distribution and abundance under global warming by extrapolation of the climate envelope may lead to serious errors."

Some SDMs have successfully incorporated interactions between species (Leathwick and Austin 2001, Leathwick 2002; Heikkinen et al. 2007, Rödder et al. 2008), and a small number have also included climate change (Araújo and Luoto 2007). Others have suggested biotic interactions will be best accounted for through models with mechanistic elements, rather than SDMs using correlation alone (Sutherst et al. 2007, Keith et al. 2008). Such studies have confirmed the importance of interspecific interactions and shown it is feasible to include them in models. However, such models require a priori recognition of important interactions, and substantial preliminary thought and work is essential before such interactions can be incorporated. As the important competitive interactions for many species are unknown or unsupported by spatial data (Sutherst et al. 2007), it seems unlikely that SDMs incorporating interspecific interactions could be routinely produced for most species soon.

\section{The appearance of unprecedented environmental domains}

As climates change new combinations of climate and other environmental parameters may appear that did not previously exist (Walker and Steffen 1997). For example, higher rainfall may begin to fall on a soil type that has not previously experienced this regime. The more climatic parameters that are included in a model, the more likely it is that novel combinations will occur in future scenarios. To predict a species' likely occurrence in these unprecedented spaces, models must make predictions outside the scope of their input data (i. e., they must extrapolate where they have no knowledge). Given that the relationship between a species' occurrence and environmental variables is typically non linear, projecting likely distributions into novel climate space is problematic. Depending on the modeling algorithm used, distributions may be over- or under-predicted in novel environmental space (Table 1).

\section{Equilibria: time lags and historic accidents}

It is often assumed that organisms are found in the environmental space that best suits their requirements, and they are in equilibrium with their environment. This assumption is implicit when observed occurrences are used to model species' distributions. In reality, it is likely that the realized niche of a species will be in a state of flux naturally. However, this dynamism is not captured in most data sets available for SDM development. In many cases, a species may not occur at a location with potentially suitable habitat because it physically cannot disperse there or is yet to arrive there. Fickle accidents of history are likely to explain a great deal about species' distributions (e.g., space preemption: Poloczanska et al. 2008, Britton-Simons 2006). Other species occur in areas to which they are not well suited (Fitzpatrick et al. 2007): in longlived species, adults may persist in areas even when conditions are no longer suitable for the 
Table 1. Factors likely to cause over- or under-estimation of the extent of species' distributions, with the application of SDMs to future climate scenarios. These conclusions assume that a basic SDM approach (i.e., correlation of distribution data with environmental data) has been applied, and no special efforts have been made to counter these factors. See text for an explanation of the reasoning.

\author{
Systematic under-estimation of distribution ("false pessimism"): \\ Interspecific interactions \\ Incomplete sampling of niche \\ Adaptation and evolution
}

Systematic over-estimation of distribution ("false optimism"):

Non-inclusion of mobility data

Non-systematic errors:

Lack of equilibria

Unprecedented environments

Scale mismatch

Non-inclusion of land-use change

Failure to distinguish cause and correlation

establishment of young (Woodward 1990). Other species will persist in habitat fragments that are too small or degraded to maintain viable populations in the long term. Over time, they are likely to disappear ("relaxation"-Diamond 1972; "extinction debt"Tilman et al. 2002).

The implications of these combined influences on SDMs projected into future climate scenarios are complex (Table 1). The incomplete occupation of suitable niche space means that models built using observed presences cannot account for the species' latent but unachieved ability to survive in other areas (i.e., under-prediction). The presence of species in areas to which they are unsuited can also cause models to over-predict species' ranges: unsuitable habitat is incorporated into the envelope, and the current "debt" is hidden in future habitat projections. Many apparent predictions of species extinction are in fact predictions of species "committed to extinction" (Lewis 2006), a commitment that may take decades or centuries to fulfil. Such issues are only sometimes acknowledged in discussions of the impact of climate change on species' distributions (e.g., Harrison et al. 2006, Lewis 2006).

\section{Species mobility}

Some species move seasonally and do not experience the climate within their range for all of the year. Many birds, for example, adjust their locations and behaviors to follow seasonal resources on a range of geographic scales (e.g., Griffioen and Clarke 2002). For seasonally mobile species, some parts of the range may temporarily experience climatic conditions beyond the tolerance of the organism. If records are used within such areas to define the species' distribution, the model will assume the species can tolerate these conditions on 
a permanent (i.e., non-seasonal) basis. In fact, the species can accommodate the existence of such conditions within its range only if alternatives are available. We anticipate that SDMs for species that move seasonally within their ranges will frequently over-predict distribution extent (Table 1), but that this effect may not be noticed until there is a sudden collapse in actual range, due to the loss of accessible seasonal refugia. To our knowledge, no one has systematically considered this complex problem, although Heikkenen et al. (2006) showed that current species-climate models could be improved if they were manipulated to account for migratory bird species' local arrival and departure times.

\section{Evolution and adaptation}

Some species may be able to evolve fast enough to alter their environmental requirements as the climate changes, particularly those with short generation times and diverse gene pools (Pearson and Dawson 2003, Räsänen et al. 2003, Harte et al. 2004, Lewis 2006, Skelly et al. 2007). Furthermore, species are made up of local populations that may be locally adapted to different portions of their range, and individuals in one part may have a different genetic constitution to those in another part. Currently, we are unable to predict a species' capacity to evolve. Species distribution models using current distributional data to predict the future are thus unlikely to incorporate evolutionary change, leading to under-prediction (Table 1).

\section{Capacity to emigrate}

As suitable ranges shift under altered climates, the ability of species to exploit new suitable habitat will depend on the dispersal of individuals or propagules. This has been a central concern of many commentators on the likely impacts of climate change on biodiversity (Hoegh-Guldberg et al. 2008). Some organisms are highly constrained in their ability to move across the landscape. Midgley et al. (2002) described proteaceous plant species in the South African fynbos that require occasional catastrophic fires to release seeds and provide germination opportunity. Seeds are typically dispersed by ants, which can only move short distances. This combination means such species will be unable to "track" any rapid climate shifts.

Most models do not take these considerations into account, and those that do have used simple assumptions (no migration, full migration; Thomas et al. 2004). Ideally, we require detailed understanding of dispersability, including distances that organisms can disperse, modes and frequency of dispersal, and how this relates to population characteristics. These parameters are only known for a tiny fraction of species (e.g., Fitzpatrick et al. 2008).

\section{Land-use change}

Humans are rarely included in models of biological systems, despite being one of the most important elements influencing contemporary biological processes. Most SDMs predicting future climate scenarios make bold (but seldom stated) assumptions about trends in human demography and land use. Accounting for future clearing, agricultural or urban intensification, or restoration work is obviously difficult (see Rouget et al. 2003, Leemans and Serneels 2004). We suggest, as have others (e.g., Jetz et al. 2007), that changed patterns of habitat fragmentation and connection are likely to have at least as large an impact as climate change in the medium term, both as problems and solutions (i.e., both over- and under-prediction of range).

\section{Methodological Problems}

\section{Incomplete sampling of niche space}

Distributional data for SDM development are frequently distributed unevenly across a species' range with respect to space, time, and environment (Thuiller et al. 2004, Phillips et al. 2009). Recurring spatial biases are characteristic of many biological survey data sets (see Frietag et al. 1998, Schulman et al. 2007), such as a tendency for higher sampling rates at accessible locations. If unrepresentative samples are used, significant areas suitable for occupancy may be omitted or not recognized in current SDMs and those projected into future climate scenarios (i.e., under-prediction, Table 1). Although some studies suffer from this problem (e. g., Erasmus et al. 2002), others limit its impact by selecting species that are restricted to a study area (e.g., Harrison et al. 2006). However, if species with narrow ranges are preferentially chosen for most modeling studies, the collective results may be biased (Lewis 2006). Recent studies have begun to describe methods to mitigate the impact of sampling biases on prediction (e.g., Schulman et al. 2007, Phillips et al. 2009). 


\section{Cause and correlation}

Strong correlation does not imply causation (Austin 2002). Climate data can be associated with many ecological phenomena for reasons other than causality (e.g., spatial proximity and mutual correlation with other variables). Strong correlations may allow climate data to predict species occurrences, even if climate has little to do with a species' distribution (Lozier et al. 2009). For instance, consider a species once widespread but now restricted to a single island as a consequence of predation. This species' distribution is not now strongly limited by climate, however, climate variables may very accurately predict its distribution in a model, as would latitude and longitude. The relative influence of current climate in the distribution of many species is unknown.

\section{Scale mismatch}

Most models that predict species' ranges under future climates require modeled climate scenarios as inputs (although some apply a uniform change; Brereton et al. 1995). Climate scenarios are derived from complex mathematical models. Some elements of climate are more tightly parameterized (e.g., temperature, ocean acidification) than others (e.g., precipitation patterns), and their accuracy and resolution have important ramifications for speciesclimate predictions (Beaumont and Hughes 2002, Watson 2008).

Many species require specific small-scale habitat attributes that are likely to be overlooked by SDMs. Topographic, geomorphic, or edaphic features (e. g., rocky cliffs, seepage areas) and the distributions of other species (e.g., as required hosts) will be crucial for many species. Most SDMs use relatively large grid cells to represent climate scenarios, often tens or even hundreds of kilometers across (e.g., Erasmus et al. 2002). Few are capable of representing small-scale features, or difficult-tocapture features such as those noted above (Williams et al. 2003). Other critical environmental variables are frequently unavailable in spatial format (e.g., groundwater resources). There are similar problems relating to temporal habitat elements. Relevant climatic events such as storms and droughts are hard to predict or represent spatially, as are seasonal biotic factors (e.g., pollinator visits; Hannah et al. 2002). The consequences of scale for SDM interpretation are complex and introduce high levels of uncertainties. We suggest these effects could cause both over- or under-prediction (Table 1).

\section{BEYOND SCIENCE: USING SDMS UNDER FUTURE CLIMATES TO MAKE DECISIONS}

In his report to the Australian Government, Garnaut (2008) described climate policy as a "diabolical problem." We cannot afford inaction or prevarication on climate change mitigation, adaptation, or policy. We believe the technical and conceptual problems facing SDMs are just as devilish, given the factors we have discussed above. But is solving these modeling problems necessary for biodiversity management in the face of climate change? How essential are SDMs for making the right decisions? We argue below that (1) SDMs have already achieved much of their potential in the climate debate, (2) that SDMs are fundamentally limited in their ability to inform decision making, (3) that some improvements may nonetheless be helpful to biodiversity managers, but (4) ultimately managers must make decisions without them.

\section{What Have SDMs Achieved So Far?}

Despite the inherent limitations on SDMs, they have clearly achieved a great deal in the climate change debate. Perhaps more than anything, SDMs have promoted ecological theory and biodiversity conservation into the non-scientific arena. They have provided clear and concise warnings, allowing biodiversity issues to permeate broader discussions of climate change. Species' extinction risk formed a key part of Stern's review of climate change impacts for the British government (2006), and numerous SDM studies were cited (e.g., Pearson and Dawson 2003, Thuiller et al. 2004, Thomas et al. 2004, McClean et al. 2005, Pearson et al. 2006).

Beyond the current climate change debate, when applied to current or past climates (avoiding some of the limitations noted above), SDMs have undoubtedly been very useful. They have helped map the distributions of cryptically similar species, revealed biogeographic patterns, contributed to our understanding of niche, suggested places to search for undetected new populations of modeled species, and helped find suitable sites for reintroduction of 
threatened species (e.g., Leathwick and Austin 2001, Leathwick 2002, Lindsay and Bayoh 2004, Broennimann et al. 2007).

\section{Pitfalls in the Use of SDMs in the Climate Debate: Perception and Precision}

The rise in prominence of SDMs has been accompanied by the rise of geographical information systems (GIS mapping software). Complex models that were once expressed as equations can readily be displayed as maps having a more immediate and striking impact to most people. Unfortunately, our ability to present error and uncertainty spatially has not kept pace (Gahegan and Ehlers 2000, MacEachren et al. 2005). We believe that maps produced by a GIS often appear misleadingly precise. There is a real risk that GIS-supported SDMs will be interpreted poorly by policy makers (among others), and that they will be given undeserved prominence in the decision-making process because of this apparent precision.

As highlighted here, some of the inherent limitations in SDMs may cause not only "noise," but systematic over- or under-estimates of future range sizes. This may translate into unjustified optimism or pessimism in the non-scientific debate. It is impossible to quantify these effects overall, but our discussion suggests that, in general, models tend to under-predict a species' range (Table 1), presenting a picture that is perhaps unduly bleak. This may be amplified or misrepresented by the popular media. When Thomas et al. (2004) reported that a large percentage of species may be "committed to extinction" within 50 years, many news agencies misreported that over a quarter of all life forms would "be extinct" by this time (Ladle et al. 2004). Over-prediction of future range (undue optimism) may also be misinterpreted in a similar way.

\section{Improving SDMs}

Given the pitfalls and limitations outlined in this report, is it reasonable to continue using SDMs for climate policy development? We believe that the answer is "Yes, sometimes." For some species, SDMs may offer good opportunities for prediction and planning. Species with generalist requirements are good candidates for using an SDM approach, including those with distributions closely tied to climate, where mobility is well understood, and where good supporting data sets exist. Some of the more thoughtful past SDM applications give hope that even complex multi-species climate change problems may be tackled using SDMs (e.g., Leathwick and Austin 2001, Leathwick 2002). We suggest the following basic rules of thumb for the development and use of SDMs:

- Continue basic biological and ecological research. It is important to determine the relative influences of climatic factors. Physiological constraints to growth and reproduction are known only for a small number of species (Hijmans and Graham 2006). When sound knowledge of the target species' ecology is known and thoughtfully catered for, the power of SDMs is impressive (examples cited above).

- Improve modeling algorithms. Where SDMs are deemed useful, it is important to use the best available methods.

- Systematically collect distribution records. The collection of absences is valuable, because many modeling routines require both absences and presences (Elith et al. 2006). New studies should be systematically planned so that geographic and environmental spaces are well sampled, and survey effort should be recorded.

- Monitor trends over time and validate projected SDMs using emerging data. For species that are amenable to SDM, models could be verified over time as future data become available. This is being done with the monitoring of European birds, where sufficient climate and distribution data are able to reveal temporal trends (Araújo et al. 2005, Gregory et al. 2009).

- Address uncertainties explicitly. When SDMs are built using modeled inputs (such as climate scenarios), uncertainty is propagated through the models. The degree of uncertainty must be communicated in a meaningful way to managers and policy makers who hope to use SDMs to make decisions.

- Be careful with maps. Most SDMs are presented as maps with "predicted future" 
distributions juxtaposed with "current" distributions (e.g., Midgley et al. 2002, Berry et al. 2002, Beaumont and Hughes 2002, Williams et al. 2003, Harrison et al. 2006, Jensen et al. 2008). They often imply local extinctions or contractions by a certain date, and these may be very misleading if they fail to portray differences between "actual extinction" and "committed extinction" (Lewis 2006). Simple changes in the presentation of data could be of great benefit. Rather than showing current and future distributions, many SDMs may be better expressed as areas where species' ranges "may expand," and where they are likely to become "marginal" in future. We also suggest using a black-and-white scale in figures, which is less open to subjective interpretation than the variety of color scales available.

\section{What Should We Do Beyond Reliance on SDMs?}

Climate change is acting in an environment already threatened by other processes (Thomas et al. 2004, Lewis 2006). For decades conservationists and managers have dealt with habitat fragmentation and degradation, introduced species and pathogens, hunting pressures, and toxins. These issues remain and many will interact and be compounded by climate change. Our climate response must be formulated with the complexity and synergism of these processes in mind. Species distribution models have put biodiversity on the climate agenda, but they need not drive our decision making at the expense of other considerations.

Acting upon these "traditional" conservation problems may often be the best and only available defence against climate change. If the effects of climate change on species include physiological stress, changing niche space, and a compulsion to move across a fragmented or hostile environment, then we can soften the impact by addressing the fundamental issues of habitat quality and habitat connectivity. These are the things that land managers are already endeavoring to achieve.

Many of the innovations honed by the use of SDMs (GIS, spatial modeling algorithms) may be used to help managers solve the traditional conservation problems noted above. Coupled with spatial modeling, GIS may help us answer a number of important questions such as the consequences of habitat fragmentation (for example, exploring how permeable the landscape currently is, and how different species "see" connectivity (McRae and Beier 2007))

\section{CONCLUSIONS}

It is important to remember that the basic problems faced by biodiversity under climate change (changing niche space, changing interactions, compulsion to move across a fragmented environment) have long been recognized in ecological theory and may be readily predicted by basic ecological principles without SDMs (e.g., Peters and Darling 1985). We must also remember that most of the things we know we can do to protect biodiversity from climate impacts are the same things currently implemented against other threats (Dale et al. 2000, Hulme 2005).

We have relied on some general ecological principles to explore the limitations of SDMs. We acknowledge that these principles themselves may change over time, and do not suggest that SDMs should be judged against a pure and perfect theoretical understanding of the biological world. Indeed, we see as one of the strengths of SDMs their ability to highlight theoretical problems and influence the theoretical landscape in which they are embedded (e.g. Broennimann et al. 2007). We doubt, however, that SDMs can advance our onground conservation efforts far beyond where we are at present.

Responses to this article can be read online at:

http://www.ecologyandsociety.org/voll5/iss 1/art8/responses/

\section{Acknowledgments:}

This paper was formulated from useful discussions with policy colleagues James Todd, David Parkes (Victorian Department of Sustainability and Environment), and Geoff Park (North Central Catchment Management Authority), and fellow scientists Canran Liu (Arthur Rylah Institute), Jane Elith (University of Melbourne), and Roger Jones (CSIRO, Victoria University). We acknowledge the 
financial assistance of North Central CMA, and the comments provided by two anonymous reviewers.

\section{LITERATURE CITED}

Araújo, M. B., and D. M. Luoto. 2007. The importance of biotic interactions for modelling species distributions under climate change. Global Ecology and Biogeography 16:743-753.

Araújo, M. B., R. G. Pearson, W. Thuiller, and M. Erhard. 2005. Validation of species-climate models under climate change. Global Change Biology 11:1504-1513.

Austin, M. P. 2002. Spatial prediction of species distribution: an interface between ecological theory and statistical modelling. Ecological Modelling 157:101-118.

Beaumont, L. J., and L. Hughes. 2002. Potential changes in the distributions of latitudinally restricted Australian butterfly species in response to climate change. Global Change Biology 8:954971.

Berry P. M., T. P. Dawson, P. A. Harrison, and R. G. Pearson. 2002. Modelling potential impacts of climate change on the bioclimatic envelope of species in Britain and Ireland. Global Ecology and Biogeography 11:453-462.

Best, A. S., K. Johst, T. Münkemüller, and J. M. J. Travis. 2007. Which species will successfully track climate change? The influence of intraspecific competition and density dependent dispersal on range shifting dynamics. Oikos 116:1531-1539.

Brereton, R., S. Bennett, and I. Mansergh. 1995. Enhanced greenhouse climate change and its potential effect on selected fauna of south-eastern Australia: a trend analysis. Biological Conservation 72:339-354.

Britton-Simmons, K. H. 2006. Functional group diversity, resource pre-emption and the genesis of invasion resistance in a community of marine algae. Oikos 113:395-401.

Broennimann, O., U. A. Treier, H. MüllerSchärer, W. Thuiller, A. T. Peterson, and A. Guisan. 2007. Evidence of climatic niche shift during biological invasion. Ecology Letters 10:701709.

Brooker, R. W., J. M. J. Travis, E. J. Clarke, and C. Dytham. 2007. Modelling species' range shifts in a changing climate: the impacts of biotic interactions, dispersal distance and rate of climate change. Journal of Theoretical Biology 245:59-65.

Connell, J. H. 1961. The influence of interspecific competition on the distribution of the barnacle Chthamalus stellatus. Ecology 42:710-723.

Crain, C. M., B. R. Silliman, S. L. Bertness, and M. D. Bertness. 2004. Physical and biotic drivers of plant diversity across estuarine salinity gradients. Ecology 85:2539-2549.

Dale, V. H., S. Brown, R. A. Haeuber, N. T. Hobbs, N. Huntly, R. J. Naiman, W. E. Riebsame, M. G. Turner and T. J. Valone. 2000. Ecological principles and guidelines for managing the use of land. Ecological Applications 10:639-670.

Davis, A. J., L. S. Jenkinson, J. L. Lawton, B. Shorrocks, and S. Wood. 1998a. Making mistakes when predicting shifts in species range in response to global warming. Nature 391:783-786.

Davis, A. J., J. L. Lawton, B. Shorrocks, and L. S. Jenkinson. 1998b. Individualistic species responses invalidate simple physiological models of community dynamics under global environmental change. Journal of Animal Ecology 67:600-612.

Diamond J. M. 1972. Biogeographic kinetics: estimation of relaxation times for avifaunas of South-west Pacific islands. Proceedings of the National Academy of Sciences of the USA 69:31993203.

Dormann, C. F. 2007. Promising the future? Global change projections of species distributions. Basic and Applied Ecology 8:387-397.

Elith, J., C. H. Graham, R. P. Anderson, M. Dudik, S. Ferrier, A. Guisan, R. J. Hijmans, F. Huettmann, J. R Leathwick, A. Lehman, J. Li, L. G. Lohmann, B. A. Loiselle, G. Manion, C. Moritz, M. Nakamura, Y. Nakazawa, J. M. Overton, A. T. Peterson, S. J. Phillips, K. Richardson, R. Scachetti-Pereira, R. E. Schapire, J. Soberon, S. Williams, M. S. Wisz, and N. E. Zimmermann. 2006. Novel methods improve prediction of species' distributions from 
occurrence data. Ecography 29:129-151.

Erasmus, B. F. N., A. S. van Jaarsveld, S. J. Chown, M. Kshatriya, and K. J. Wessels. 2002. Vulnerability of South African animal taxa to climate change. Global Change Biology 8:679-693.

Fielding, A. H., and J. F. Bell. 1997. A review of methods for the assessment of prediction errors in conservation presence/absence models. Ecological Conservation 24:38-49.

Fitzpatrick, M. C., A. D. Gove, N. J. Sanders, and R. R. Dunn. 2008. Climate change, plant migration, and range collapse in a global biodiversity hotspot: the Banksia Proteaceae of Western Australia. Global Change Biology 14:1-16.

Fitzpatrick, M. C., J. F. Weltzin, N. J. Sanders, and R. R. Dunn. 2007. The biogeography of prediction error: why does the introduced range of the fire ant over-predict its native range? Global Ecology and Biogeography 16:24-33.

Freitag, S., C. Hobson, H. C. Biggs, and A. S. van Jaarsveld. 1998. Testing for potential survey bias: the effect of roads, urban areas and nature reserves on a southern African mammal data set. Animal Conservation 1:119-127.

Gahegan, M., and M. Ehlers. 2000. A framework for the modelling of uncertainty between remote sensing and geographic information systems. ISPRS Journal of Photogrammetry and Remote Sensing 55:176-188.

Garnaut, R. 2008. The Garnaut climate change review: final report. Commonwealth of Australia. Cambridge University Press, Melbourne, Australia.

Gregory, R. D., S. G. Willis, F. Jiguet, P. Vorísek, A. Klvanova, A. van Strein, B. Huntley, Y. C. Collingham, D. Couvet, and R. E. Green. 2009. An indicator of the impact of climatic change on European bird populations. PLoS One 4:e4678.

Griffioen, P. A., and M. F. Clarke. 2002. Largescale bird-movement patterns evident in eastern Australian atlas data. Еmu 102:99-125.

Guisan, A., and W. Tuiller. 2005. Predicting species distribution: offering more than simple habitat models. Ecology Letters 8:993-1009.
Hampe, A. 2004. Bioclimate envelope models: what they detect and what they hide. Global Ecology and Biogeography 13:469-471.

Hannah, L., G. F. Midgley, T. Lovejoy, W. J. Bonds, M. Bush, J. C. Lovett, D. Scott, and F. I. Woodward. 2002. Conservation of biodiversity in a changing climate. Conservation Biology 16:264 268.

Hannah, L., and B. Phillips. 2004. Extinction-risk coverage is worth inaccuracies. Nature 430:141.

Harrison P. A., P. M. Berry, N. Butt, and M. New. 2006. Modelling climate change impacts on species' distributions at the European scale: implications for conservation policy. Environmental Science and Policy 9:116-128.

Harte, J., A. Ostling, J. L. Green, and A. P. Kinzig. 2004. Climate change and extinction risk. Nature 430:U3.

Heikkinen, R. K., M. Luoto, M. B. Araújo, R. Virkkala, W. Thuiller, and M. T. Sykes. 2006. Methods and uncertainties in bioclimatic envelope modelling under climate change. Progress in Physical Geography 30:751-777.

Heikkinen, R. K., M. Luoto, R. Virkkala, R. G. Pearson and J.-H. Körber. 2007. Biotic interactions improve prediction of boreal bird distributions at macro-scales. Global Ecology and Biogeography 16:754-763.

Hoegh-Guldberg, O., L. Hughes, S. McIntyre, D. B. Lindenmayer, C. Parmesan, H. P. Possingham, C. D. Thomas. 2008. Assisted colonization and rapid climate change. Science 321:345-346.

Hijmans, R. J., and C. H. Graham. 2006. The ability of climate envelope models to predict the effect of climate change on species distributions. Global Change Biology 12:2272-2281.

Hulme, P. E. 2005. Adapting to climate change: is there scope for ecological management in the face of a global threat? Journal of Applied Ecology 42:784-794.

Hutchinson, G. E. 1957. Concluding remarks. Cold Spring Harbour Symposium on Quantitative Biology 22:415-427. 
Jensen R. A., J. Madsen, M. O'Connell, M. S. Wisz, H. Toemmervik, and F. Mehlum. 2008. Preiction of the distribution of Arctic-nesting pinkfooted geese under a warmer climate scenario. Global Change Biology 14:1-10.

Jetz, W., D. S. Wilcove, and A. P. Dobson. 2007. Projected impacts of climate and land-use change on the global diversity of birds. PLoS Biology 5:1211-1219.

Kearney, M. R., B. L. Phillips, C. R. Tracy, K. A. Christian, G. Betts, and W. P. Porter. 2008. Modelling species distributions without using species distributions: the cane toad in Australia under current and future climates. Ecography 31:423-434.

Keith, D. A., H. R. Akçakaya, W. Thuiller, G. F. Midgley, R. G. Pearson, S. J. Philips, H. M. Regan, M. B. Araújo, and T. G. Rebelo. 2008. Predicting extinction risks under climate change: coupling stochastic population models with dynamic bioclimatic habitat models. Biology Letters 4:560-563.

Ladle, R. J., P. Jepson, M. B. Araújo, and R. J. Whittaker. 2004. Dangers of crying wolf over risk of extinctions. Nature 428:799.

Leathwick, J. R. 2002. Intra-generic competition among Nothofagus in New Zealand's primary indigenous forests. Biodiversity and Conservation 11:2177-2187.

Leathwick, J. R., and M. P. Austin. 2001. Competitive interactions between tree species in New Zealand's old-growth indigenous forests. Ecology 82:2560-2573.

Leemans, R., and S. Serneels. 2004. Understanding land-use change to reconstruct, describe or predict changes in land cover. GeoJournal 61:305-307.

Lewis, O. 2006. Climate change, species-area curves and the extinction crisis. Philosophical Transactions of the Royal Society of London $B$ 361:163-171.

Lindsay, S. W., and M. N. Bayoh. 2004. Mapping members of the Anopheles gambiae complex using climate data. Physiological Entomology 29:204209.
Lozier, J. D., P. Aniello, and M. J. Hickerson. 2009. Predicting the distribution of Sasquatch in western North America: anything goes with ecological niche modeling. Journal of Biogeography, in press.

MacEachren, A. M., A. Robinson, S. Hopper, S. Gardner, R. Murray, M. Gahegan, and E. Hetzler. 2005. Visualizing geospatial information uncertainty: what we know and what we need to know. Cartography and Geographic Information Science 32:139-160.

Massot, M., J. Clobert, and R. Ferrière. 2008. Climate warming, dispersal inhibition and extinction risk. Global Change Biology 14:461469.

McClean, C. J., J. C. Lovett, W. Küper, L. Hannah, J. Henning Sommer, W. Barthlott, M. Termansen, G. F. Smith, S. Tokumine, and J. R. D. Taplin. 2005. African plant diversity and climate change. Annals of the Missouri Botanical Garden 922:139-152.

McRae, B. H., and P. Beier. 2007. Circuit theory predicts gene flow in plant and animal populations. Proceedings of the National Academy of Sciences USA 104:19885-19190.

Midgley, G. F., L. Hannah, D. Millar, M. C. Rutherford, and L. W. Powrie. 2002. Assessing the vulnerability of species richness to anthropogenic climate change in a biodiversity hotspot. Global Ecology and Biogeography 11:445-451.

Ostendorf, B., D. W. Hilbert, and M. S. Hopkins. 2001. The effect of climate change on tropical rainforest vegetation pattern. Ecological Modelling 145:211-224.

Parmesan, C. 1996. Climate and species' range. Nature 382:765-766.

Parmesan, C. 2006. Ecological and evolutionary responses to recent climate change. Annual Review of Ecology, Evolution and Systematics 37:637-669.

Pearson, R. G., and T.P. Dawson. 2003. Predicting the impacts of climate change on the distribution of species: are bioclimatic envelope models useful? Global Ecology and Biogeography 12:361-371. 
Pearson, R. G., W. Thuiller, M. B. Araújo, E. Martinez-Meyer, L. Brotons, C. McClean, L. Miles, P. Segurado, T. P. Dawson, and D. C. Lees. 2006. Model-based uncertainty in species range prediction. Journal of Biogeography 2006:1-8.

Peters R. L., and J. D. S. Darling. 1985. The greenhouse effect and nature reserves. Bioscience 35:707-717.

Phillips, S. J., R. P. Anderson, and R. E. Schapire. 2006. Maximum entropy modeling of species geographic distributions. Ecological Modelling 190:231-259.

Philips, S. J., M. Dudik, J. Elith, C. H. Graham, A. Lehmann, J. Leathwick, and S. Ferrier. 2009. Sample selection bias and presence-only distribution models: implications for background and pseudoabsence data. Ecological Applications 19:181-197.

Phillips, S. J., P. Williams, G. Midgley, and A. Archer. 2008. Optimizing dispersal corridors for the cape Proteaceae using network flow. Ecological Applications 185:1200-1211.

Poloczansca, E. S., S. J. Hawkins, A. J. Southward, and M. T. Burrows. 2008. Modelling the response of populations of competing species to climate change. Ecology 89:3138-3149.

Räsänen, K., A. Laurila, and J. Merilä. 2003. Geographic variation in acid stress tolerance of the moor frog Rana arvalis. I. Local adaptation. Evolution 57:352-362.

Rödder, D., M. Veith, and S. Lötters. 2008. Environmental gradients explaining the prevalence and intensity of infection with the amphibian chytrid fungus: the host's perspective. Animal Conservation 11:513-517.

Rouget, M., D. M. Richardson, R. M. Cowling, J. W. Lloyd, and A. T. Lombard. 2003. Current patterns of habitat transformation and future threats to biodiversity in terrestrial ecosystems of the Cape Floristic Region, South Africa. Biological Conservation 112:63-85.

Schulman, L., T. Toivonen, and K. Ruokolainen. 2007. Analysing botanical collecting effort in Amazonia and correcting for it in species range estimation. Journal of Biogeography 34(8):13881399.
Skelly, D. K., L. N. Joseph, H. P. Possingham, L. K. Freidenburg, T. J. Farrugia, M. T. Kinnison, and A. P. Hendry. 2007. Evolutionary responses to climate change. Conservation Biololgy 21:13531355.

Stern, N. 2006. The economics of climate change: the Stern review. Cabinet Office, Her Majesty's Treasury, Cambridge University Press, Cambridge, UK.

Sutherst, R. W., G. F. Maywald, and A.S. Bourne. 2007. Including species interactions in risk assessments for global change. Global Change Biology 13:1843-1859.

Thomas, C. D., A. Cameron, R. E. Green, M. Bakkenes, L. J. Beaumont, Y. C. Collingham, B. F. N. Erasmus, M. Ferraria de Siqueira, A. Grainger, L. Hannah, L. Hughes, B. Huntley, A. S. van Jaarsvels, G. F. Midgley, L. Miles, M. A. Ortega-Huerta, A. T. Peterson, O. L. Phillips, and S. E. Williams. 2004. Extinction risk from climate change. Nature 427:145-148.

Thuiller, W., L. Brotons, M. B. Araújo, and S. Lavorel. 2004. Effects of restricting environmental range data to project current and future species distributions. Ecography 27:165-172.

Tilman, D., R. M. May, C. L. Lehman, and M. A. Nowak. 2002. Habitat destruction and the extinction debt. Nature 371:65-66.

Vos, C., P. Berry, P. Opdam, H. Baveco, B. Nijhof, J. O'Hanley, C. Bell, and H. Kuipers. 2008. Adapting landscapes to climate change: examples of climate-proof ecosystem networks and priority adaptation zones. Journal of Applied Ecology 45:1722-1731.

Walker, B., and W. Steffen. 1997. An overview of the implications of global change for natural and managed terrestrial ecosystems. Conservation Ecology 1(2): 2. [online] URL: http://www.ecology andsociety.org/vol1/iss 2/art2/.

Watson, A. J. 2008. Certainty and uncertainty in climate change predictions: what use are climate models? Environmental and Resource Economics 39:37-44.

Williams, S. E., E. E. Bolitho, and S. Fox. 2003. Climate change in Australian tropical rainforests: 
and impending environmental catastrophe. Proceedings of the Royal Society of London B 270:1887-1892.

Woodward, F. I. 1990. The impact of low temperatures in controlling the geographical distribution of plants. Philosophical Transactions of the Royal Society of London B 326:585-593. 